\title{
CMEARTICLE Doctor, I sprained my ankle
}

\begin{abstract}
Mr Chan hobbled into your consultation room complaining of a painful right ankle. You found out that he had inverted his ankle on uneven ground but was able to slowly walk home by himself after the injury. He wanted to know whether he had broken any bones and when he could resume training for his first marathon, which was taking place in two weeks' time.
\end{abstract}

\section{HOW COMMON IS THIS IN MY PRACTICE?}

The ankle is the second most commonly injured body part during sports. Ankle sprains constitute the majority of ankle injuries.(1) They involve at least one of the ankle ligaments, with injuries ranging from a micro tear to a complete tear of the ligament or group of ligaments. ${ }^{(2)}$ Ankle sprains are classified by location into lateral, medial and high ankle sprains.

Lateral ankle sprains, which are the most common, usually result from inversion stress of a plantar-flexed foot. ${ }^{(3)}$ The most commonly involved ligament in ankle sprains is the anterior talofibular ligament (ATFL). The ATFL, calcaneofibular ligament and posterior talofibular ligament together form the fan-shaped lateral ankle ligament complex, and a stronger force may injure the latter two as well. ${ }^{(4)}$ Pain, swelling and tenderness are typically located anterior and inferior to the lateral malleolus.

Isolated medial ankle sprains are uncommon, as the medial deltoid ligament complex is the strongest of the ankle ligaments. However, deltoid ligament injuries can occur simultaneously when there is injury of the lateral ligament complex. An avulsion fracture of the medial malleolus may also occur. Pain and bruising in deltoid ligament injuries are usually located inferior to the medial malleolus.

A high ankle sprain (syndesmotic sprain) involves the anterior, posterior and transverse tibiofibular ligaments, and the interosseous membrane. ${ }^{(5)}$ These structures are important to ankle stability and injury may lead to chronic complications. The region of pain and tenderness in a high ankle sprain is different from that of a lateral ligament injury. It is located in the groove between the distal fibula and tibia, superior to the lateral malleolus.

\section{HOW RELEVANT IS THIS TO MY PRACTICE?}

An ankle sprain results in pain, limited mobility/exercise and loss of school/work days. The acute responsibilities of the attending clinician include: (a) stratifying the risk of fracture; (b) pain management; (c) providing advice/certification for loss of function; and (d) assessing any long-term implications.

\section{Acute management}

It is important to ascertain three parts of the patient's history, namely: (a) the mechanism of injury and the likely force involved; (b) the patient's ability to weight-bear after the injury; and (c) any previous injury to the same ankle. Physical examination can be guided by the mechanism of injury. Any swelling, bruising, loss of function and relevant special tests (e.g. squeeze test, external rotation, anterior drawer or talar tilt test) should be clearly documented together with the aforementioned history. The Ottawa ankle rules (Table I) is a useful aid to guide assessment of the risk of ankle fracture and the need for radiography. ${ }^{(6)}$

\section{Table I. The Ottawa ankle rules. ${ }^{(6)}$}

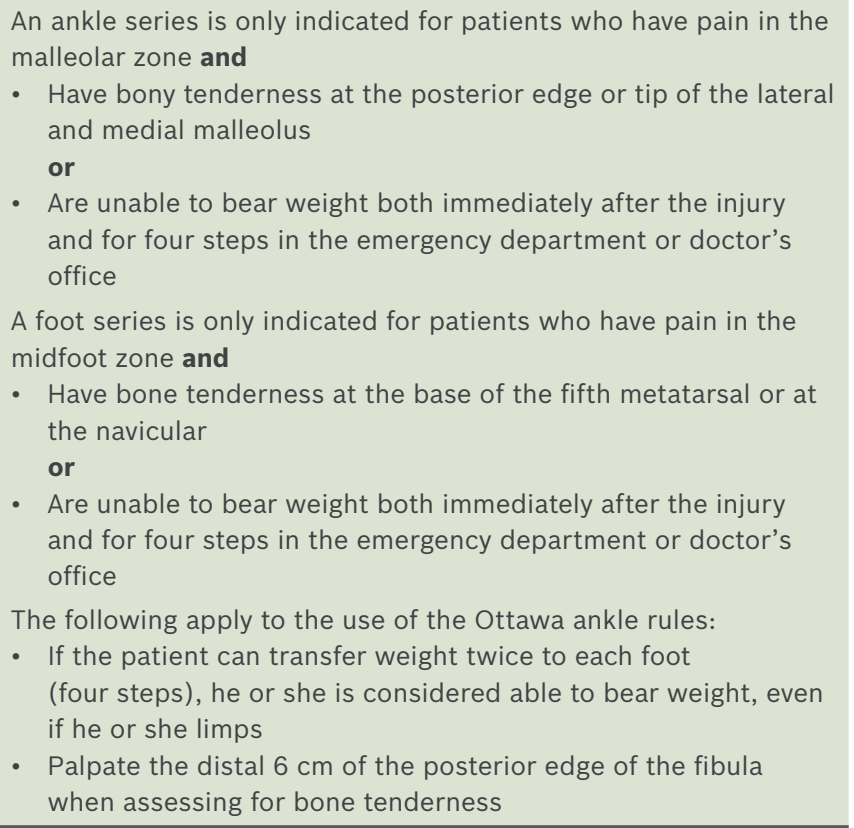




\section{Management}

Initial management options can be abbreviated by the acronym "RICE".

1. Rest by limiting weight bearing for 1-2 days until able to walk with a normal gait.

2. Ice pack application or cold water immersion is recommended for 15-20 min every $2-3 \mathrm{hr}$ for the first 48 hours, or until swelling is improved, whichever comes first.

3. Compression with an elastic bandage or compression stocking early.

4. Elevate the injured ankle above the level of the heart to further alleviate swelling.

No particular nonsteroidal anti-inflammatory drugs (NSAIDs) has been shown to be superior, nor are there studies comparing NSAIDs with non-NSAID analgesics (e.g. acetaminophen). ${ }^{(7-8)}$ Therefore, it is still unclear whether anti-inflammatory treatment is important. Exercises to maintain the ankle's range of motion should be started early. For mild to moderate sprains, gradual rehabilitation may start as soon as the initial pain and swelling have subsided, and slowly stepped up. Proprioceptive training programmes are effective at reducing the incidence of a repeat ankle sprain. ${ }^{(9)}$

\section{Common pitfalls in managing ankle sprains}

A common misconception among patients is that they have fully recovered from their injury once their pain and swelling have subsided. However, there may be an increased risk of pain and/or re-injury if mechanical instability or loss of functional mechanisms has occurred. Mechanical instability results from ligament laxity, which is often associated with a partial to complete tear. Ankle injuries may also involve functional instability, i.e. loss of proprioceptive or neuromuscular defense. The risk of recurrent ankle injuries is often a combination of both mechanical and functional disabilities. ${ }^{(3)}$ Both mechanical instability and functional instability may require treatment either with a ligament repair and/or rehabilitation programme.

Furthermore, attending doctors should encourage their patients to return for a review should their condition persist or worsen. It has been shown that clinical examination a few days after ankle injury improves the diagnosis of ligamentous injuries and instability, with a $95 \%$ positive predictive value of ligament rupture for the triad of (a) pain on palpation of the ATFL; (b) lateral discolouration due to haematoma; and (c) a positive anterior drawer sign. ${ }^{(10)}$

\section{TAKE HOME MESSAGES}

1. History-taking to determine the mechanism of injury, the patient's ability to walk after injury, and any previous injury to the ankle is important.

2. Perform a careful physical examination, paying particular attention to the areas covered by the Ottawa ankle rules.

3. Patients with a high ankle sprain need special tests, such as the squeeze test or external rotation stress test, to exclude a syndesmosis injury.
4. Patients suspected of a syndesmosis injury will benefit from magnetic resonance imaging (MR) imaging and an orthopaedic review, preferably with an ankle specialist.

5. Patients with injuries involving the neurovascular bundle (e.g. distal findings of decreased sensation, motion, or circulation) should require emergency evaluation.

6. Orthopaedic referral is necessary for a fracture, dislocation or subluxation, syndesmosis injury, tendon rupture, wound penetrating into the joint, and in cases of persistent pain and/or instability after initial treatment.

7. Initial treatment consists of rest, ice, compression and elevation (RICE), early mobilisation, and an ankle support with early weight-bearing.

8. The risk of recurrent ankle injuries is often a combination of both mechanical and functional disabilities.

After assessing Mr Chan, you reassured him that he was unlikely to have sustained any broken bones. You advised him to "RICE" his joint, certified him unfit for work for the next two days, and arranged for a physiotherapy appointment in four days' time. You also encouraged him to return for a review if his condition worsened or did not show improvement. You reminded him that gradual mechanical and functional rehabilitation was required, and that rushing to regain optimal performance too soon (i.e. his first marathon in two weeks' time) may increase his risk of recurrent sprains and chronic ankle dysfunction.

ABSTRACT Ankle sprains constitute the majority of ankle injuries, and result in pain, limited mobility/exercise and loss of school/work days. Ankle sprains involve at least one of the ankle ligaments and range from a micro tear to complete tear of the ligament or group of ligaments. The most common mechanism of ankle sprains is inversion stress of a plantar-flexed foot, while the most frequently injured ligament is the anterior talofibular ligament. The attending clinician needs to stratify the risk of fracture through history-taking and physical examination, manage the pain, assess long-term complications and provide certification for rest and recovery. The Ottawa ankle rules may be useful. Graduated exercises to maintain the ankle's range of motion should be started early, after the resolution of initial pain and swelling. The risk of recurrent ankle injuries is often a combination of both mechanical and functional disabilities.

Keywords: ankle injury, ankle sprains, syndesmotic injury

\section{REFERENCES}

1. Fong DT, Hong Y, Chan LK, Yung PS, Chan KM. A systematic review on ankle injury and ankle sprain in sports. Sports Med 2007; 37:73-94.

2. Delahunt E, Coughlan GF, Caulfield B, et al. Inclusion criteria when investigating insufficiencies in chronic ankle instability. Med Sci Sports Exerc 2010; 42:2106-21.

3. Kobayashi T, Gamada K. Lateral ankle sprain and chronic ankle instability: a critical review. Foot Ankle Spec 2014; 7:298-326. 
4. Nitz AJ, Dobner JJ, Kersey D. Nerve injury and grades II and III ankle sprains. Am J Sports Med 1985; 13:177-82.

5. Mak MF, Gartner L, Pearce CJ. Management of syndesmosis injuries in the elite athlete. Foot Ankle Clin 2013; 18:195-214.

6. Stiell IG, Greenberg GH, McKnight RD, et al. Decision rules for the use of radiography in acute ankle injuries. Refinement and prospective validation. JAMA 1993; 269:1127-32.

7. Cukiernik VA, Lim R, Warren D, et al. Naproxen versus acetaminophen for therapy of soft tissue injuries to the ankle in children. Ann Pharmacother 2007; 41:1368-74.
8. Kayali C, Agus H, Surer L, Turgut A. The efficacy of paracetamol in the treatment of ankle sprains in comparison with diclofenac sodium. Saudi Med J 2007; 28:1836-9.

9. Schiftan GS, Ross LA, Hahne AJ. The effectiveness of proprioceptive training in preventing ankle sprains in sporting populations: A systematic review and meta-analysis. J Sci Med Sport 2014 Apr 26. pii: S1440-2440(14)00074-7. doi: 10.1016/j.jsams.2014.04.005. [Epub ahead of print]

10. van Dijk CN, Lim LS, Bossuyt PM, Marti RK. Physical examination is sufficient for the diagnosis of sprained ankles. J Bone Joint Surg Br 1996; 78:958-62. 


\section{SINGAPORE MEDICAL COUNCIL CATEGORY 3B CME PROGRAMME} (Code SMJ 201410C)

1. Ankle sprains may or may not involve any ankle ligament injuries.

2. Ankle sprains are classified according to three broad locations, the forefoot, hindfoot and lower leg.

3. Medial ankle sprains resulting from supination of the feet are the most commonly involved injuries, as the medial deltoid ligament is the weakest of all the ankle ligaments.

4. Lateral ankle sprains are usually a result of inversion stress of a plantar-flexed foot.

5. The first injured ligament in most ankle sprains is the posterior talofibular ligament.

6. The anterior talofibular, calcaneofibular and posterior talofibular ligaments together form the fan-shaped lateral ankle ligament.

7. An avulsion fracture of the medial malleolus is more common than isolated medial deltoid ligament injuries.

8. A high ankle sprain (syndesmotic sprain) involves the anterior tibiofibular, posterior tibiofibular and transverse tibiofibular ligaments, and the interosseous membrane.

9. These structures (mentioned in question 8) are important to ankle stability, and injury may lead to chronic complications.

10. The attending clinician needs to stratify the risk of fracture, manage the pain, assess long-term complications, and provide certification for rest and recovery.

11. A history of weight-bearing after ankle injury is not important, as the patient's baseline pain tolerance varies too much.

12. According to the Ottawa ankle rules, if a patient needs to limp when transferring weight twice to each foot (four steps), he or she is considered unable to bear weight.

13. According to the Ottawa ankle rules, a patient who is unable to bear weight immediately after injury and in the doctor's presence, and has pain in the malleolar zone or midfoot, will need to undergo radiography to exclude a fracture.

14. Distal toe numbness, a frequent finding in acute ankle sprains, should be observed at home and reviewed if it persists for more than three days.

15. Orthopaedic referral is necessary for a fracture, dislocation or subluxation, syndesmosis injury, tendon rupture, wound penetrating into the joint, and in cases of an uncertain diagnosis.

16. Initial treatment for ankle sprains consists of rest, ice, compression and elevation (RICE), early mobilisation, and support orthosis with early weight-bearing.

17. Ibuprofen has been shown in several small studies to be the nonsteroidal anti-inflammatory drug (NSAID) of choice and has been shown to be superior to other drugs in the NSAID class.

18. NSAIDs have not been shown to be superior to non-NSAID analgesics such as acetaminophen in the treatment of ankle sprains.

19. After the resolution of initial pain and swelling, exercises to maintain the ankle's range of motion should be started early and slowly stepped up.

20. The risk of recurrent ankle injuries is often a combination of both mechanical and functional disabilities.

\section{Doctor's particulars:}

Name in full

MCR number

Specialty:

Email address

\section{SUBMISSION INSTRUCTIONS:}

(1) Log on at the SMJ website: http://www.sma.org.sg/publications/smjcurrentissue.aspx and select the appropriate set of questions. (2) Provide your name, email address and MCR number. (3) Select your answers and click "Submit".

\section{RESULTS:}

(1) Answers will be published in the SMJ December 2014 issue. (2) The MCR numbers of successful candidates will be posted online at the SMJ website by 9 December 2014. (3) Passing mark is $60 \%$. No mark will be deducted for incorrect answers. (4) The SMJ editorial office will submit the list of successful candidates to the Singapore Medical Council. (5) One CME point is awarded for successful candidates.

Deadline for submission: (October 2014 SMJ 3B CME programme): 12 noon, 2 December 2014. 